\title{
USURPACIÓN, RECLAMOS SOCIALES Y SOLUCIONES PENALES*
}

\author{
Encroachment of public space, social demands and penal solutions
}

Resumen: El trabajo cuestiona el uso particular del derecho penal en sociedades desiguales y en contra de grupos desaventajados con la intención de limitar su acceso a derechos sociales constitucionales. Más específicamente, defiendo la ocupación de espacios públicos como consecuencia de la falla de los gobiernos en solucionar el problema del acceso a la vivienda digna. Voy a argumentar, por un lado, que debemos distinguir entre un reclamo social y un delito para evitar el uso del derecho penal en determinados casos. Por otra parte, voy a criticar el uso particular del concepto de igualdad aplicado por los defensores de la "solución del castigo".

Palabras Clave: igualdad - derechos sociales - derecho penal - castigo.

\footnotetext{
* Presenté algunas versiones de este trabajo en distintos lugares durante los últimos años, por lo que quisiera agradecer a los participantes por sus preguntas, comentarios y discusiones ocurridas en el Seminario del Departamento de Derecho Constitucional, Universidad del Externado de Colombia, a los participantes del 7 mo. Congreso Latinoamericano de Ciencia Política, organizado por la Asociación Latinoamericana de Ciencia Política en Bogotá (Colombia), también a aquellos con los que discutí en el XI Congreso Nacional de Ciencia Politica, organizado por la Sociedad Argentina de Análisis Político y la Universidad Nacional de Entre Ríos en Paraná (Argentina) y en el Second ISA Forum of Sociology organizado por la International Sociological Association y la Universidad de Buenos Aires en Buenos Aires (Argentina). Una primera versión de este trabajo fue presentada también en la Conferencia Anual de la Association of Legal and Social Philosophy en 2011, en la Universidad de Warwick (Reino Unido) en donde me pude beneficiar de los comentarios y preguntas de Antony Duff, Victor Tadros, Massimo Renzo, Ben Saunders, Leticia Morales y Verónica Rodríguez Blanco. Este trabajo también es parte del Proyecto de Investigación DeCyT (DCT 1206), 2012-2014 (Facultad de Derecho, Universidad de Buenos Aires) "La respuesta del Estado frente a los reclamos ciudadanos. Dos formas de pensar la protesta en Argentina: criminalización o reconocimiento de la ciudadanía". Quisiera agradecer a los integrantes del proyecto que ayudaron a clarificar cuestiones puntuales del trabajo: Leticia Vita, Mariana Kohan, Martín Aldao, Federico de Fazio, Santiago Roldán y Gonzalo Penna. También quisiera agradecer a los estudiantes del curso de la Facultad de Derecho de la Universidad de Palermo, "El castigo en contextos de desigualdad" donde este paper fue presentado y discutido. Una versión anterior de este trabajo fue publicada en G.Beade/L.Vita, Criminalización de la Protesta. La repuesta del Estado frente a los reclamos ciudadanos (AdHoc, Buenos Aires, 2015).

** Abogado graduado en la Universidad de Buenos Aires, Master en Derecho en la Universidad de Palermo y Doctorando en Derecho en la Universidad de Buenos Aires, Buenos Aires, Argentina. Correo electrónico: gbeade@,derecho.uba.ar
}

Este artículo fue recibido el 12 de noviembre de 2015, siendo aprobada su publicación el 18 de enero de 2016. 


\begin{abstract}
The paper deals with a particular use of the criminal law in unequal societies against disadvantages groups attempting to limit their access to social rights. More specifically, I will defend here the occupation of public places as a consequence of the failure of the government to solve the problem of housing. I will argue on the one hand that we must distinguish between a social claim and a crime and avoid the use of criminal law in certain cases. On the other hand, I will criticize the particular use of the concept of equality use by the defenders of the "punishment solution".
\end{abstract}

Keywords: equality - social rights - criminal law - punishment.

En este trabajo me interesa mostrar la forma en la que se resuelven judicialmente los casos que involucran la usurpación de un terreno público. Como sabemos, en general, ocupar un terreno ajeno implica la comisión de un delito. En muchos casos estas acciones están motivadas por la inacción del Estado en brindar respuestas ante reclamos de sus ciudadanos ante la imposibilidad de acceder al derecho a tener una vivienda. Sin embargo, en estos casos la respuesta de los jueces es la aplicación del derecho penal. El argumento para distinguir entre un reclamo social y la comisión de un delito, entienden estos jueces, se basa en el respeto al principio de igualdad que vincula tanto a quien ocupa un terreno ajeno como al resto de los conciudadanos. En este sentido, este ideal de igualdad demandaría un deber moral de no cometer delitos que todos debemos respetar dentro de una comunidad democrática, por el cual quien no lo respeta debe ser castigado, sin excepción. Mi intención aquí será cuestionar esa utilización del argumento de igualdad y dar razones para señalar que en contextos donde existen grandes márgenes de desigualdad el Estado no debería aplicar un castigo penal a quien usurpa un terreno público.

\title{
1. Reclamos y usurpación
}

Quisiera aquí presentar un caso ficticio, pero que se parece mucho a casos que todos conocemos: un grupo de personas, cansadas de esperar durante años las respuestas del gobierno ante sus reclamos para la obtención de una vivienda digna, decide usurpar un parque público abandonado hace años por el propio gobierno y utilizado, solo ocasionalmente, por los vecinos de la zona. ${ }^{1}$ Este grupo de personas actúa ante una situación de desesperación acuciante en la pretensión de lograr para su familia al menos un lugar decente para vivir, lo que supone dejar de vivir en las casillas y bajo los puentes que habitan al momento de la usurpación. Su objetivo es construir, de a poco y de la forma que se pueda, una vivienda en ese parque. Este

\footnotetext{
${ }^{1}$ Un estudio sobre un caso ocurrido en Argentina durante el año 2010 puede verse en CRAVINO et.al (2012).
} 
grupo de personas no recibe ningún tipo de ayuda y su situación de pobreza extrema ha sido provocada por decisiones en las que ellos no han participado. Esto quiere decir que su situación no es por su culpa. Ante la necesidad de obtener una vivienda digna para vivir junto a su familia su desesperación los lleva a instalarse directamente en el parque con todas sus pertenencias y con sus hijos. Debido a la falta de una respuesta estatal, concretar su objetivo es visto por ellos como algo legítimo y justificado moralmente.

Luego de los primeros movimientos que evidencian la usurpación por parte de los que llamaré en adelante "los usurpantes", un grupo de vecinos decide llamar a la policía. La policía acude y con una autorización judicial desaloja violentamente el predio. Esta autorización judicial tomó en consideración que la usurpación es un delito establecido en el Código Penal y procedió a la utilización de la fuerza para desalojar y detener preventivamente a "los usurpantes" quienes ahora, además de haber perdido el lugar que creyeron que tenían para construir su vivienda, deberán afrontar un proceso penal en su contra. En lo que sigue me interesaría pensar argumentos para mostrar por un lado, las dificultades a las que podrían estar sometidos algunos jueces para poder diferenciar entre la comisión de un delito y brindar una respuesta a un reclamo de un derecho social constitucional; luego me voy a concentrar en analizar los argumentos que podrían dar "los usurpantes" y las respuestas (si pueden dar alguna) que implica la aplicación del derecho penal (lo que denomino solución del castigo).

\section{2. ¿Comisión de un delito o reclamo por el cumplimiento de un derecho social?}

La pregunta que me interesaría responder aquí se vincula con cierta imposibilidad de los jueces, en particular los jueces penales, para resolver cuestiones como las que he planteado en la sección anterior de una forma que permita partir de la base de entender la usurpación no como un delito, sino como un reclamo social o, como en este caso, la reacción ante el incumplimiento de una promesa política. Me interesa pensar las razones por las que no sería posible salir del derecho en estos casos y evitar así la aplicación de un castigo por hechos como estos.

En primer lugar diría que el rol que cumplen jueces y fiscales penales les impide ver más allá de lo que las normas le indican. Esto es, ante la comisión de un delito, estos funcionarios judiciales tendrían la obligación legal, como funcionarios públicos, de tratar la cuestión, en principio, como un delito. En particular y en los casos de usurpación de un terreno la configuración del delito es bastante sencilla, según lo que podría establecer un código penal, esto es, el ingreso en un terreno ajeno con la finalidad de permanecer allí por un tiempo prolongado. ${ }^{2}$ Se podría

\footnotetext{
${ }^{2}$ No estoy particularmente interesado en ninguna legislación penal concreta. La referencia al delito de usurpación puede ubicarse en cualquier legislación penal más o menos moderna.
} 
argumentar que no es tarea de los jueces y fiscales penales establecer los motivos que llevaron a esas personas a usurpar un terreno ajeno, como así tampoco las circunstancias previas en las que viven y las complejidades a las que se someten si finalmente decidieran hacerlo. Su obligación, podríamos decir, es determinar si están ante un delito o no y qué tareas deben llevar a cabo para poder establecerlo, determinar los culpables y castigarlos conforme al derecho que se encuentre vigente.

Todo esto, sería sencillamente lo que diría un funcionario judicial para evitar ingresar en la cuestión que a mi interesa discutir acá. Mi pregunta estaría centrada en todo aquello que está detrás de los hechos que le interesan al derecho penal. Me refiero a las circunstancias acuciantes que sufren personas que no tienen hogar, la razones que tienen para decidir ocupar un terreno que no les pertenece, la frutración que supone no tener una respuesta del gobierno local, esto ¿siempre es irrelevante? ¿es correcto que sea así? Si los jueces no pueden distinguir esta cuestión: ¿quién podría hacerlo? ¿qué opción queda para "los usurpantes" cuyas pocas opciones los llevan a ocupar un terreno público y es esa misma desesperación lo que los lleva a ser criminalizados penalmente? Es probable que un juez que identifique las circunstancias de los hechos como un problema social, también tendría problemas para justificar su decisión de no considerar ( $\mathrm{y}$ no investigar) los delitos involucrados en los hechos. Sin embargo, pareciera ser que, en general, los jueces son partidarios de la aplicación de la solución penal, incluso por razones distintas de las que se propician desde otros ámbitos. Vuelvo sobre esta circunstancia más adelante e intento dar una respuesta persuasiva sobre el punto.

\section{Sobrecriminalización de la desigualdad}

Asumo aqui que "los usurpantes" son grupos heterogéneos, conformados por grupos de personas desaventajadas que incluyen ciudadanos que viven en graves condiciones de pobreza, que quieren dejar atrás su propia precariedad y mejorar sus perspectivas de futuro. Es evidente que casi la única posibilidad de cambiar esa situación podría darse con la intervención estatal, lo que incluye la ayuda del gobierno para poder construir o adquirir su propia vivienda. Como hemos visto, el favorecimiento de la "solución penal" es impulsada, en primer lugar, por miembros de la misma comunidad a la que pertenecen "los usurpantes" bajo el argumento de que debemos respetar y aplicar la ley. ${ }^{3}$ Esto muestra que para una parte de la comunidad no hay otra alternativa para resolver un conflicto que no sea a través de la fuerza del derecho y en imponer la coerción que inflige el derecho penal. Así, una consencuencia necesaria que se deriva de este razonamiento es la aplicación del proceso de desalojo lo cual incluye una violencia extrema, daños y lesiones físicas. Luego, la consecuencia necesaria del uso de la fuerza (y ante su resistencia) parece ser la persecución penal y, en ciertos casos, el encarcelamiento preventivo de alguno de "los usurpantes".

\footnotetext{
${ }^{3}$ Para una explicación sobre los usos de este tipo de argumentación, véase WALDRON (2000).
} 
Esta circunstancia se acrecienta a partir de la idea de que estos grupos de personas pueden transformarse en enemigos, para lo cual necesitan un trato específico que difiere del que se brinda a quienes son considerados y tratados como ciudadanos. Sobre esto, habría mucho que decir, pero por el momento solo quisiera señalar que estos grupos desaventajados tienen cierta vulnerabilidad para ser sancionados penalmente que otros ciudadanos no tienen y su imposibilidad de ajustarse a las normas los haría pasibles de ser tratados de una forma diferente. ${ }^{4}$ De este modo, la ausencia de respeto por el derecho, los miedos del anarquismo y el peligro de ser el próximo dañado constituyen las bases de apelar a las "soluciones" del derecho penal. ${ }^{5}$

La sobrecriminalización y también la expansión del derecho penal son dos conceptos que han sido desarrollados en discusiones durante los últimos años. Este debate que ha tenido un amplio desarrollo tanto en Europa como en los Estados Unidos, se origina a partir de la proliferación de leyes que se crearon luego de los atentados ocurridos el 11 de septiembre de 2001. Los problemas son similares y los argumentos, en parte, también. Básicamente los autores que cuestionan la sobrecriminalización y la expansión del derecho penal se refieren críticamente a la creación de leyes penales y la mayor criminalización de conductas lo cual, entre otras cosas, acarrea mayores encarcelamientos, pero también mayor limitación a las libertades individuales de los ciudadanos. ${ }^{6}$ La intuición que defiendo aquí es que en comunidades como las nuestras, en donde los problemas de terrorismo internacional son más aislados, la aplicación de conceptos como el de sobrecriminalización tiene otra perspectiva que se vincula con nuestros problemas particulares. En definitiva, a partir de casos de usurpación como los que he descrito defiendo la idea de que existiría una sobrecriminalización en contextos de desigualdad que estaría centrado en el uso concreto del derecho y no en la proliferación de leyes penales (la llamada "inflación penal"), sin embargo el sentido sería básicamente el mismo que se propone en otros contextos: castigamos muchas personas, muy duramente y destructivamente.

Es este uso del castigo sobre estas personas que me parece moralmente cuestionable. Desde un punto de vista centrado en vida comunitaria, el hecho de que reconozcamos que existe una brecha amplia de desigualdad y que sintamos empatía sobre los que peor están debería llevarnos a repensar no solo nuestras prácticas de inculpar y castigar, sino también los modos en los que podríamos colaborar para mejorar a aquellos que lo necesitan. Pensar desde este punto de vista nos obliga a tomar en cuenta al otro como un conciudadano, como uno de

\footnotetext{
${ }^{4}$ JAKOBS (2005); también PAWLIK (2010).

5 Acerca de esta asunción vinculada específicamente con la ausencia de una vivienda ver FAILER (2000).

${ }^{6}$ Sobre la idea de sobrecriminalización ver HUSAK (2007) y DUFF (2010b).
} 
nosotros, no como un extraño con el que no tenemos nada que ver. Digo algo sobre esto más adelante. Sin embargo, quisiera mostrar que incluso desde el punto de vista que propongo aquí existen argumentos para sostener la solución del castigo. Presento esas ideas en lo que sigue.

\section{Castigo y la comunidad inclusiva}

Existe aún una argumentación tendiente a mostrar que es necesario castigar a aquellos que cometen delitos o infracciones penales, sin perjuicio de su situación precaria, debido a que son miembros de nuestra comunidad. ${ }^{7}$ En este sentido, si los consideramos miembros de nuestra comunidad, es necesario castigarlos por las normas que nosotros construimos y decidimos elegir. De otro modo, los estaríamos excluyendo y tratando como extraños o, peor, ignorándolos como conciudadanos. Así, la necesidad del castigo se basa en la inclusión y, en alguna medida, tomar en serio a aquellos que cometen delitos penales. Las ideas de la cohesión y la autoridad cobran un gran sentido en esta formulación, puesto que es necesario generar un respeto determinado por nuestras decisiones comunitarias así como el reconocimiento de la autoridad que tiene sobre nosotros la ley penal.

Esta noción de comunidad se vincula estrechamente con la idea de responsabilidad y tiende a señalar que no es posible concebir un ideal comunitario sin el reproche y el castigo. El castigo a aquellos que cometen delitos o infracciones es una muestra del reconocimiento de estas personas como miembros de la comunidad, así como la identificación de que estamos dentro de una colectividad en donde premiamos y reprochamos a todos los que lo merecen, sin distinción. Discuto en lo que sigue esta noción de comunidad y señalo los problemas que esta posición tiene para ser defendida en contextos de desigualdad como los que aquí trato de presentar.

\section{El uso del derecho penal y la obligación moral de seguir todas las reglas legales}

Me gustaría en esta sección defender algunas de las acciones descritas en el ejemplo inicial, me refiero a la ocupación de lugares públicos en particular en contextos de desigualdad. Sobre este punto voy a argumentar contra el uso del derecho penal desde dos puntos de vista: el primero estará centrado en el argumento de que casos de usuparción o de las acciones llevadas a cabo por "los usurpantes" no son asuntos del derecho penal. Mi segundo punto estará relacionado con los argumentos morales que "los usurpantes" podrían brindar contra las acciones violentas del Estado, esto es, razones personales contra la posibilidad de ser castigados. Este segundo punto está dirigido a responder por qué, en cualquier caso y en cualquier situación, todos los ciudadanos de una

\footnotetext{
${ }^{7}$ En este sentido, MALAmUd GOTI (2011).
} 
comunidad estaríamos obligados a obedecer todas las reglas legales penales existentes. Sin embargo, mi preocupación no es con las regulaciones legales. Por esta razón tampoco estoy tratando de dar argumentos relacionados con justificaciones o excusas legales, porque no es el punto que quisiera desarrollar aquí, aunque también creo que es posible encontrar una respuesta plausible para justificar esas conductas en la legislación penal actual. ${ }^{8}$ En este sentido, no voy a ensayar aquí una teoría general de la desobediencia legal ni tampoco a dar argumentos contra su responsabilidad o intentar desacreditar la autoridad del derecho penal en estos casos. ${ }^{9}$ En cambio, mi objetivo será algo más modesto: quisiera defender en estos casos concretos de usurpación, estas acciones concretas de usurpar tierras abandondas o parques deshabitados desde estos dos puntos de vista vinculados a las obligaciones estatales y sobre las de los ciudadanos en contra del uso del derecho penal en estos casos.

Cuando un cierto Estado no provee soluciones para eliminar o disminuir la desigualdad y la pobreza castigar a alguien que vive en condiciones de extrema pobreza como aquellos que deciden usurpar un parque público supone un castigo penal injusto. Por lo demás, no puede ser negado que quienes viven en una comunidad democrática deben cumplir con una variedad de deberes y obligaciones. Existen también obligaciones que corresponden al Estado en general y a los gobiernos en particular, vinculados con la provisión de bienestar e igualdad para todos los ciudadanos. Si el Estado no satisface esas condiciones previas sería hipócrita en castigar a grupos desaventajados que viven en circunstancias injustas creadas por él. ${ }^{10}$ En este sentido, no se trata de señalar que existen ciudadanos que están fuera del derecho, sino que por el contrario es el Estado el que se encuentra fuera de la legalidad al incumplir con la satisfacción de necesidades básicas. ${ }^{11}$ En tanto las obligaciones del Estado se encuentren incumplidas su status moral para exigir determinados comportamientos, pero particularmente para imponer un castigo penal se encuentra severamente debilitado. No quisiera apartarme mucho del caso que origina el trabajo, por eso retomo la cuestión de la usurpación.

El Estado en los casos de usurpación no tiene un status moral para imponer un castigo, siendo que es el propio Estado el que causa esa situación previa de desigualdad. Así, en las condiciones que acabo de enunciar el argumento del "castigo inclusivo" tiene que ser dejado de lado. No es posible afirmar que el castigo incluye a ciudadanos dentro de una comunidad si es el Estado y los miembros de la propia comunidad quienes son responsables de esta situación que

\footnotetext{
${ }^{8}$ En contra de esto MALAMUd Goti (2005).

${ }^{9}$ Sobre los problemas de responsabilidad criminal ver TADROS (2009). Para un acercamiento a la obligación de obedecer el derecho basado en el contrato social clásico ver REIMAN (2007).

${ }^{10}$ Una fundamentación acabada de este argumento puede verse en DUFF (2001); en particular relacionado con grupos desaventajados HUDSON (1996); TADROS (2009), p. 409; GARGARELLA (2011).

${ }^{11}$ Una idea similar puede verse en ALEGRE (2010).
} 
deben enfrentar "los usurpantes". Asumiendo este punto vista, mi argumentación aquí ira por un camino algo diferente. Más allá de la imoralidad del Estado para imponer un castigo a ciudadanos desesperados que invaden un parque púbico para asegurarse un lugar donde vivir, quisiera referirme al problema de cómo decidimos usar la ley en estos casos. Mi preocupación es con la posición de los funcionarios judiciales que sostienen que solo pueden aplicar la ley establecida para este delito cuando se les presentan situaciones análogas a las que describí. Estoy interesado en dar argumentos contra el malentendido que supone estar atrapado por el derecho, lo cual supone que solo podemos aplicarlo sin tomar en cuenta las condiciones particulares del caso. En definitiva mi punto sería, por un lado, reconocer esta imposición de un castigo inmoral e injusto y, por el otro, cuestionar una actitud de los jueces y fiscales que les impide reconocer esta cuestión y actuar de un modo diferente. Estas acciones de jueces y fiscales constituyen una mala concepción del positivismo jurídico. Al parecer los funcionarios judiciales argumentan que no tienen otra posibilidad que aplicar la legislación vigente y que si existen problemas con dichas leyes no es algo sobre lo que ellos puedan manifestarse, sino que, por el contrario, este sería un asunto de los legisladores que no las modifican.

Esta actitud de "mirar hacia otro lado" en contextos de privaciones severas es moralmente cuestionable y deja a las personas abandonas y sin la posibilidad de tener otras chances para evadir el castigo penal. Además, contradice el punto de vista democrático en el que las comunidades deben basarse, porque falla en tratar a sus conciudadanos con igual respeto y consideración. ${ }^{12}$ Sin embargo, mi argumento no debería ser solo un argumento moral, sino también uno democrático. Debería argumentar en ambos sentidos para intentar solucionar el problema práctico.

Pienso que habría varias formas de reclamar al Estado para que los funcionarios judiciales resuelvan este tipo de conflictos de otra forma. Las posibilidades de pensar soluciones es bien amplia, sin embargo me gustaría concentrarme en un punto: esto no es un asunto del derecho penal. Tengo tres argumentos para defender esta afirmación: el primero, es acerca de la responsabilidad del Estado sobre los grupos desaventajdos. Como señalé previamente la situación de pobres e inmigrantes no es debido a sus malas decisiones o su propia imprudencia, sino que es debido a decisiones políticas. La respuesta lógica debería ser que esto requiere una solución política no una no solución brindada por el derecho penal. Está claro que no podemos construir casas o crear empleos con el derecho penal. Fácticamente el derecho penal no nos provee de ese tipo de soluciones o de soluciones, en general. En palabras de Antony Duff, el castigo es reconocimiento y respuesta a daños y males que nuestros conciudadanos sufrieron. ${ }^{13}$ En este sentido deberíamos rechazar este uso

\footnotetext{
${ }^{12}$ DufF (2001), p. 183.

${ }^{13}$ DuFF (2010a), pp. 15-16..
} 
del derecho penal que no toma en cuenta ningún tipo de sufrimiento y que es utilizado, en parte, para satisfacer reclamos de alguna parte de la comunidad y, en otra, para ahorrarse el dinero que supondría la satisfacción del derecho a la vivienda de "los usurpantes" y de muchos otros. Entonces, deberíamos detenernos para evitar la situación crítica y afrontar el problema de igualdad.

Adicionalmente mi segundo argumento es que, según entiendo, los casos de usurpación de lugares públicos no traen aparejados ningún daño y, además, no hay ninguna víctima identificable. Asimismo, los derechos que pueden ser presentados como violados por la ocupación son débiles en contra de la extrema necesidad de los ocupantes. Alguien podría argumentar que "me sería imposible correr por el parque todas las mañanas, una actividad que realizo hace varios años", o "no puedo salir a pasear con mi perro por el parque", o "no quiero ver a esas personas enfrente de mi casa", o cualquier argumento por el estilo. Se podría decir también que estas personas están tomando el parque para su propio interés y que, en definitiva, es un espacio que pertenece a toda la comunidad. Sin embargo la respuesta simple contra ese argumento es que también el resto de la comunidad es responsable por el tratamiento sin el debido respeto y consideración que les debemos como conciudadanos. Cuando tenemos un grupo de personas que se encuentra en una situación crítica, como la de aquellos que no tienen un lugar donde vivir, hay argumentos que no pueden jugar ningún rol. Es nuestro interés por el otro lo que debería movernos para intentar resolver, exigir o al menos no censurar determinados tipos de conductas, entre ellas, claro, las usurpaciones como las que he planteado. Por lo tanto, esta carencia no nos deja en la mejor posición para juzgar moralmente o inculpar a los ocupantes por sus actos. En resumen, no hay un daño moral en tratar de sobrevivir en situaciones tan difíciles como las que tienen que afrontar los ocupantes y, por otra parte, el resto de la comunidad no tiene un reclamo moral que tienda a preservar la desigualdad. De otro modo: ¿deberíamos dejarlos morir, porque son desafortunados? ¿Deberían morir para ser reconocidos como mártires o como testimonio de nuestra desigualdad?

El tercer argumento se vincula con la respuesta legal que ensayan jueces y fiscales para proceder a impulsar el uso y la aplicación del derecho penal. El problema evidente es que ellos solo creen que las normas jurídicas que pueden aplicar en casos de usurparción son las normas penales. La falta de reconocimiento de un derecho constitucional a obtener una vivienda digna se hace presente en esta decisión interpretativa. Interpretar que únicamente es aplicable una respuesta penal en un reclamo social implica negar indirectamente la existencia del derecho a la vivienda. Esto no solo es moralmente reprobable también es incorrecto legalmente en particular en constituciones en donde esto se encuentra previsto expresamente. Es por eso que creo que argumentar que la legalidad impone la aplicación del derecho penal responde a una intepretación incorrecta del derecho y una negación de un derecho constitucional superior y aplicable a casos como el que origina este trabajo. 
Sin embargo, como señalé previamente, no estoy particularmente interesado en presentar soluciones prácticas o legales. Empero, sería posible pensar también en soluciones que no tuvieran como premisa la utilización del derecho penal. Se podría pensar en la intervención de organismos administrativos o, quizá mejor, la intervención de organismos políticos o gubernamentales para empezar a resolver la cuestión programando, en casos como estos, políticas públicas de mediano y largo plazo para resolver los problemas habitacionales. El reconocimiento de que estamos ante un problema no relacionado con el derecho penal es una necesidad que debemos reconocer para evitar castigar a personas solo por el hecho de su mala fortuna. El Estado no está en el mejor lugar para imponer un castigo penal como señalé es hipócrita en no reconocer que, en definitiva, todo es culpa suya y tampoco los ciudadanos tienen legitimado su reclamo con sus conciudadanos ocupantes. En definitiva, no existe un derecho para intentar mantener la desigualdad que sufren los otros. Así, tratar de argumentar, sobre la base de una igualdad hipotética en donde nadie viola las reglas legales de la comunidad, para acusar e inculpar a aquellos que lo hacen implica un juicio moral equivocado sobre la igualdad. No es posible pensar la igualdad desde un punto de vista formal, esto es, bajo la afirmación de que todos somos iguales antes la ley; la igualdad ante la ley es solo un aspecto que desplaza la idea importante de que la igualdad debe ser considerada bajo otros presupuestos y, en particular, sobre casos concretos.

El caso planteado tiende a mostrar esta circunstancia: si estamos ante personas que, por circunstancias ajenas a su voluntad, se encuentran en una situación muy desfavorable que nadie parece estar dispuesto a remediar no estamos moralmente habilitados a afirmar que estamos en igualdad de condiciones con ellos. Claramente no lo estamos y, al menos, debemos pensar de qué manera podemos ayudar a mejorar su situación, en particular si sentimos empatía con su realidad y creemos que, como miembros de una comunidad política, tenemos una obligación moral de ayudarlos. El reconocimiento de su derecho constitucional a tener una vivienda y la reticencia a aplicar la ley penal parecen ser buenas ideas para empezar a pensar la cuestión.

\section{Conclusión}

El reconocimiento de la desigualdad de la comunidad en la que vivimos debería llevar necesariamente a reconocer que hay personas que están peor que otras y que muchas de las cosas que hacen deben ser tratadas de otra forma. En particular y en casos en los que la usurpación es lo que debe discutirse, la solución no puede provenir del derecho penal, quizá ni siquiera del derecho. Como señalé durante el texto, el problema a enfrentar debe ser considerado desde un punto de vista vinculado a la solución de problemas sociales y al desarrollo de políticas públicas. Es por eso que, para poder llegar a soluciones como las que propongo, debemos rechazar la "soluciones penales" y que también debemos cuestionar a jueces y fiscales que evitan salirse de lo que dicen las normas legales, como si su trabajo 
consistiera en desconocer todo aquello que está circunscrito por una realidad que nos indica que podrían estar tomando soluciones injustas. 
Beade - Usurpación, reclamos sociales y soluciones penales

\section{BIBLIOGRAFÍA}

* Alegre, Marcelo (2010): Igualdad, Derecho y Politica, Fontamara, México.

* Cravino, et.al. (2012): Racismo, violencia y politica. Pensar el Indoamericano, dos años después, Polvorines, Universidad de Gral. Sarmiento.

* Duff, Anthony (2001). Punishment, communication, and community, Oxford University Press, Oxford.

* _ (2010a). "Inaugural Address: Towards a Theory of Criminal Law?" Proceedings of the Aristotelian Society Supplementary, Volume lxxxiv.

* _ (2010b). "A criminal law for citizens", Theoretical Criminology 14 (3).

* Failer, Judith (2000): "Homelessness in the Criminal Law", in Heffernan and Kleinig (ed.) From Social Justice to Criminal Justice. Poverty and the Administration of Criminal Law. Oxford University Press, New York.

* Gargarella, Roberto (2011): "Penal Coercion in Contexts of Social Injustice" 5 Criminal Law and Philosophy.

* Hudson, Bárbara (1996): "Punishing the poor: a critique of the dominance of legal reasoning in penal policy and practice", en Penal theory and practice (Duff, A., Marshall, S., Dobash, R. and Dobash R. eds.), Manchester University Press, Manchester.

* Husak, Douglas (2007): Overcriminalization. Oxford University Press, Oxford.

* Jakobs, Gunther (2005): "Derecho penal del ciudadano y del enemigo" en Jakobs/Cancio Meliá, Derecho penal del enemigo, Hammurabi, Buenos Aires.

* Malamud-Goti, Jaime (2005): "La justificación de los delitos de los desposeídos", SELA 2005, Ediciones Del Puerto, Buenos Aires.

* _ (2011): ¿Es posible el mundo sin responsabilidad? Notas sobre responsabilidad y comunidad", en Revista jurídica de Buenos Aires - 2011: Testimonio de derecho penal. Homenaje a Andrés José D'Alessio (Antonini Mónica A. - Divito Mauro A. coordinadores).

* PAWLIK, Michael (2010): La libertad institucionalizada. Estudios de Filosofía jurídica y Derecho penal, Marcial Pons, Madrid.

* Reiman, Jeffrey (2007): "The Moral Ambivalence of Crime in an Unjust Society" 26 Criminal Justice Ethics 3.

* Tadros, Víctor (2009): "Poverty and Criminal Responsibility" 43 Journal of V alue Inquiry 391.

* Waldron, Jeremy (2000): "Why Indigence Is Not a Justification" in Heffernan and Kleinig (ed.) From Social Justice to Criminal Justice. Poverty and the Administration of Criminal Law. 